\title{
Towards a Learning Curve Theory for Batch Production
}

\author{
A. P. Chatzimichali and V. D. Tourassis \\ Department of Production Engineering and Management \\ Democritus University of Thrace, Xanthi, Greece \\ axatzimi@pme.duth.gr
}

\begin{abstract}
Consumer attitudes and fashion trends often impose severe constraints in manufacturing. When market needs for varied product designs lead to product competition for a place in the production schedule, batch size and available production time are depressed. Due to frequent setups and retooling, quality issues arise that hold back the line from a full ramp up. Consequently, the major advantage of quality through learning in mass production is often compromised. In this paper, we stipulate that in batch production the process of industrial learning becomes more complex and thus the archetypal exponential or power curve is not sufficiently rich to describe it. Specifically, we demonstrate that the learning phenomenon appears in double guise: both within and between batches. Actual production data from the fashion-conscious ceramic tile industry provide sufficient support for our premise about the dynamic nature of learning in batch production.
\end{abstract}

Keywords - Learning curves, batch production, tile manufacturing.

\section{INTRODUCTION}

Mass manufacturing has emerged as the premier method of production not only because of the economies of scale it can achieve, but primarily because of the perceived quality premium it can provide. The observation that the performance of a task or a process improves over time or repetition is central to the theory of learning.

This 'practice makes perfect' approach has been the focus of attention in many diverse fields, from psychology to computer science and from economics to engineering. In mass manufacturing, the concept of learning has been widely used to characterize production parameters that span areas as diverse as cost reduction [1], production yield [2], [3], quality improvement [4], [5], product innovation [6], [7] and production scheduling [8].

Irrespective of the area of application, the theory of learning attempts to describe the evolution over time of the pertinent parameter through a single, typically exponential, function (i.e., the learning curve). Extensive data fitting is then employed to estimate the assumed constant rate of increase (or decay). Implicit to this approach is the hypothesis that the process at hand has been observed long enough that it can be considered settled [9].

In batch manufacturing, though, the production process has relatively short duration but tends to be repeated at random intervals. As customer attitudes and market trends typically fluctuate over time, it is quite common to see identical products being re-introduced several times in the production line. The re-appearance of a product at such distinct intervals poses interesting questions regarding the validity of the basic tenets of learning curve theory.

There are very few published works, however, that deal with learning theory in batch production. Towill's time-constant model [10], Globerson's batch time forecasting [11] and Jaber and Bonney's optimum production lot-size for new products [12] are three early attempts to incorporate learning in a theoretical batch production framework. The scarcity of empirical data to verify or dispute the corresponding models is a major handicap. There is thus a clear need for empirical learning curve research and for industrial data that will allow for the development and testing of learning models.

In this paper, actual production data from the ceramic tile industry are presented to enable a new discussion regarding the role of learning in batch production. Tile manufacturing is a prototypical example of a batch industrial process that is subject to the whims of fashion, from the cyclical trends to the fickle customer demands.

In a previous study, we applied the learning curve theory in the ceramic tile industry with the objective of forecasting new product behavior based on data from past production runs [13]. The analysis revealed some broad patterns of the potential behavior of new products, but due to the wide band of variation in the predicted intervals, their use for practical purposes remained problematic. Indeed, varied learning rates were observed for identical products from the same production facility. Analyzing the industrial data, however, provided strong hints that the learning phenomenon is much richer in batch production and that it exhibits distinct behavior within and between batches for mature products.

In this paper, we attempt to assess the learning phenomenon in batch manufacturing by filtering out effects that can be attributed to specific manufacturing lines and to product type idiosyncrasies. Thus, to control for diverse production variables such as manufacturing environment, line arrangement, human resources or even distinct organizational culture, we collected production data over time from a single facility and a specific production line.

The long-term objective is to develop an expert system to generate a reliable estimate of the final performance of a batch by using the concept of learning. Such an expert system will be an invaluable tool for 
addressing the manufacturing complexities of batch production lines.

\section{THE CASE OF TILE MANUFACTURING}

\section{A. Complexity and uncertainty}

The ceramic tile industry, in addition to the quality issues it faces due to frequent set-ups, struggles with high degrees of uncertainty and complexity that often cause production lines to work below their maximum production capacities.

A traditional problem the industry deals with is that often tile designs exhibit non-normative behavior and even a slight variation on the manufacturing or the decorative process can cause serious waste. The latter increases the uncertainty of the system, as production personnel often disagree on the causes for a particular production problem. For instance, while chromatic deviation of a tile's design is often subjective, the variation can be attributed to the raw materials used or to the kiln settings employed. Lacking a direct way to pinpoint the true cause of a variation from the norm is typical in a number of other industries as well [14].

Furthermore, due to the fact that tile production is a serial and continuous process, problems and defects that are experienced at any machine or production stage are transmitted to other machines and stages causing cumulative defects and capacity loss.

Plant personnel have to content with ambiguity and the high levels of complexity tile production demonstrates. In addition, when new products are introduced to the shop floor, the production process gets even more complicated.

\section{$B$. The case of new and mature products}

As all new products are designed and developed in the R\&D laboratory using manual machinery, a variety of problems uncover when these new products enter the full scale production in autonomous lines, since it is difficult to success the exact same manual design specifications in an automated line. Numerous design flaws are discovered in early manufacturing stages, while most engineering changes on the ramp-up of new products are motivated by manufacturability concerns. When problems like these arise, corrective actions are undertaken (equipment modification, recipe or even design change), some of which can have sizable, or perhaps temporary, negative effects on the quality performance. This effect was also observed in high-tech industries [15] and makes the learning phenomenon even more complex for new products.

Mature products, on the other hand, have been reintroduced several times in the production line. The company has invested time and effort, in order to surpass the difficult ramp-up procedure and has already controlled and stabilized parameters that may cause potential defects.
Consequently, the more mature a product is, the more the company understands its production behavior. Production data are smoother with not many fluctuations, while finally the forecasting of product's future quality performance based on its learning curve would be easier.

In the next Section the methodology of the case-study is being presented. In order to eliminate the complexities that can be attributing to new products, we concentrate on the performance of mature products.

\section{METHODOLOGY}

To analyze and understand the role of learning in the ceramic manufacturing industry, we study actual learning curves of mature products. The selected data indented for learning curve building were raw production data from a specific production line. Furthermore, as production environment is crucial for tile's performance, we selected the newest production line of the plant in order to eliminate production diversities occurred from old machinery.

Extending the traditional learning curve that focuses on the optimization of cycle time or cost, we adopt a quality-oriented curve, in compliance with recent literature approaches on quality-learning curves [3], [4], [16], [17], [18]. In addition, as it is a common practice to work with raw production data when attempting to build learning curves [19], [20], data remained unfiltered in order not to loose any additional information from smoothing.

Figure 1 demonstrates the learning curves of three mature products codified as $\mathrm{H}, \mathrm{S}$ and $\mathrm{X}$. In all cases, we demonstrate two batches, each in different time horizon, as a function of shift number and square meters of tile production. Dotted lines represent square meters of tiles that enter in the quality control phase and continuous lines represent best-quality (A sort) production flow, just after the quality sorting. Red curve lines are the learning curves of the best-quality performance flow.

To facilitate the modeling of production data and the formulation of the learning curves, we selected the simple yet functional power law that has traditionally been used to pattern learning behavior [20]. The simple power law model is considered to be the first learning curves that appeared in the literature [21] and also the most cited one.

$$
y=a \cdot x^{b}
$$

$\mathrm{y}=$ best quality tiles in $\mathrm{m}^{2}$ per shift

$\mathrm{x}=$ number of shifts

$\mathrm{a}=$ constant

$\mathrm{b}=$ slope constant - learning rate

This choice of the power law was also motivated by the data fit difficulties encountered in our previous study [13] where similar learning curve data were formulated using the exponential law. 


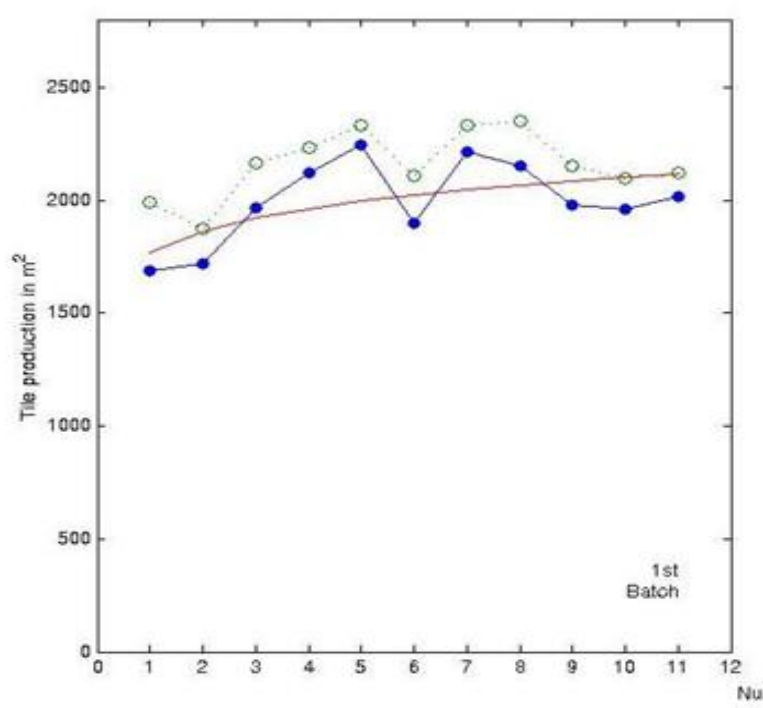

Tive H
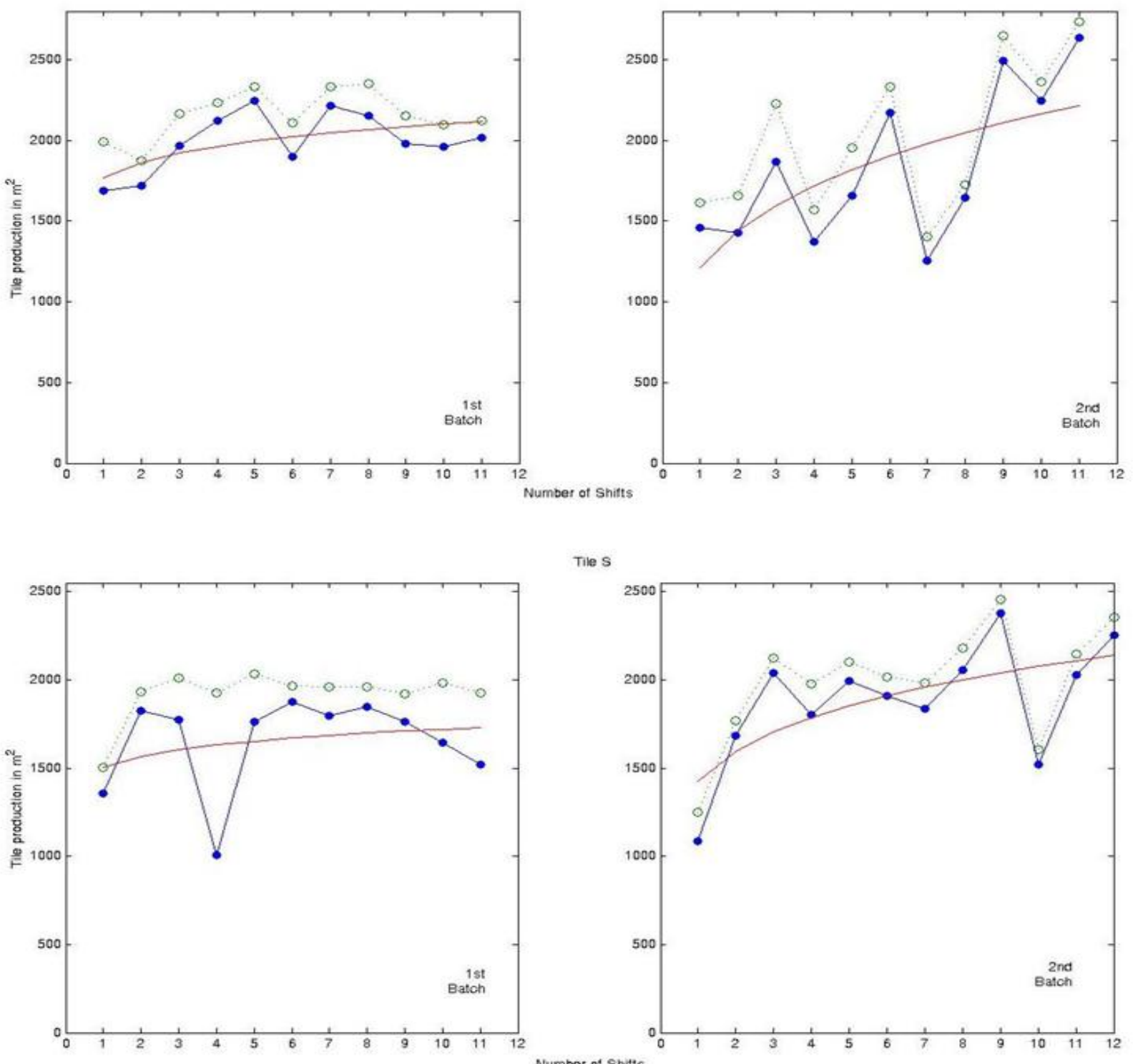

Tile $\mathrm{S}$
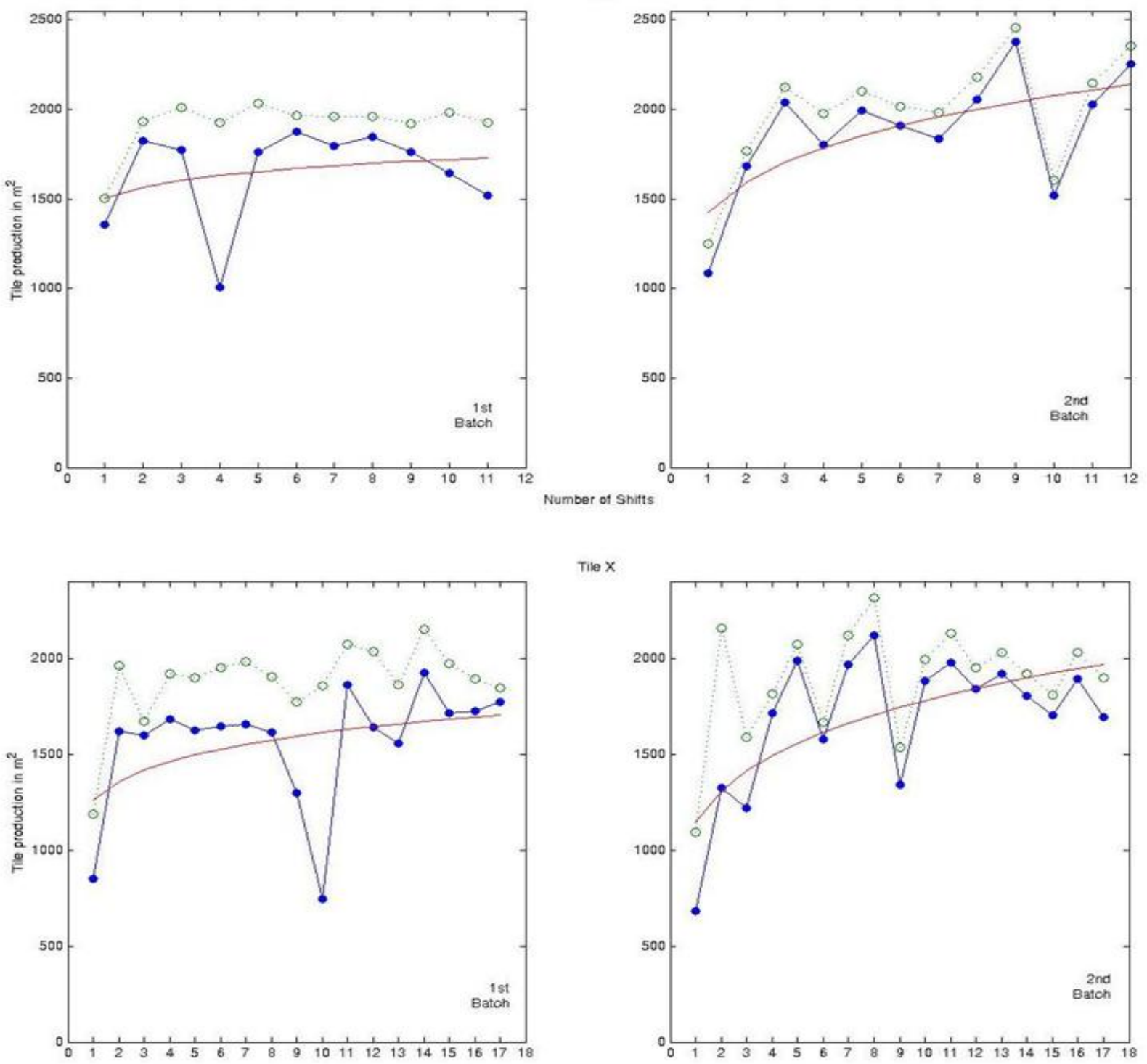

Tile $\mathrm{X}$

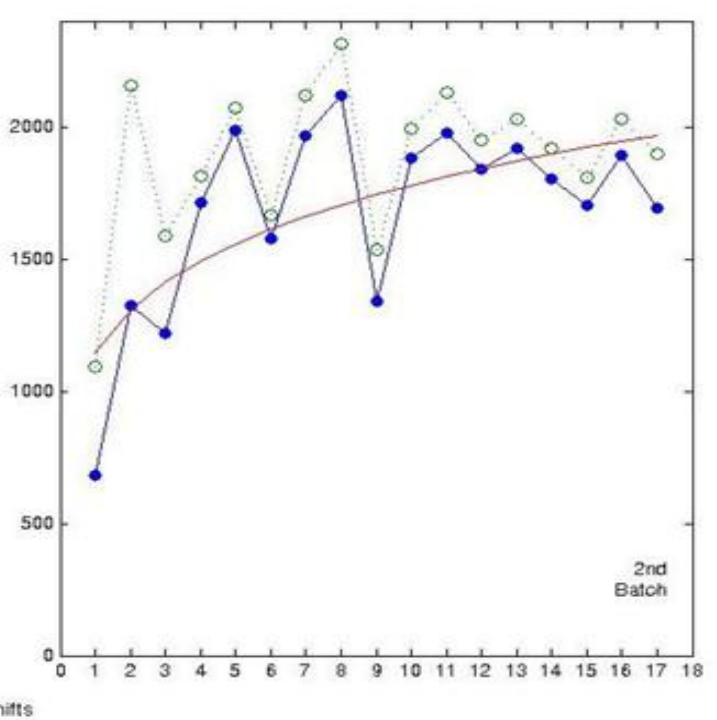

Figure 1 The performance of tiles $\mathrm{H}, \mathrm{S}$ and $\mathrm{X}$ 
A careful inspection of the three production data couples in Fig. 1, reveals a notable similar behavior in these tiles. All products demonstrate stronger learning characteristics in their second production batch. By taking a closer look in Table 1 we can observe that the learning rate in every second batch is boosted.

Considering that all these products have been produced many times before in the same production environment, one would expect that their production process has been fully mastered and that the learning rates will show no difference from batch-to-batch. Instead of this, the rate of learning grows faster from batch-to-batch. This behavior may mean that the learning advantage the process gained in previous batches is temporarily lost and regained in a faster rate.

Table 1 Learning Curve parameters

\begin{tabular}{|c|c|c|c|}
\hline & $\begin{array}{c}\text { Batch } \\
\text { No }\end{array}$ & $\begin{array}{c}\text { Learning Rate } \\
\mathbf{b}\end{array}$ & $\begin{array}{c}\text { Constant } \\
\mathbf{a}\end{array}$ \\
\hline \hline Tile H & $1^{\text {st }}$ & 0.075 & 1769 \\
\hline \hline & $2^{\text {nd }}$ & 0.252 & 1210 \\
\cline { 2 - 4 } \multicolumn{3}{|c|}{} \\
\hline Tile S & $1^{\text {st }}$ & 0.058 & 1505 \\
\hline \hline & $2^{\text {nd }}$ & 0.164 & 1423 \\
\cline { 2 - 4 } & \multicolumn{3}{|}{} \\
\hline Tile X & $1^{\text {st }}$ & 0.107 & 1262 \\
\hline \hline & $2^{\text {nd }}$ & 0.192 & 1146 \\
\hline
\end{tabular}

These data provide strong hints that a macroscopic phenomenon exists behind the simple learning curve. A phenomenon appears both as learning within and learning between batches. To fully comprehend the system's behavior, this study highlights the need to embody both effects in a new model in order to provide an insight into the learning process.

Fitted learning curves, have trouble to forecast the complex, underlying dynamics of tiles' performance. In the next Section we are turning to the literature to identify and discuss similar learning behaviors.

\section{LEARNING CURVE THEORY IMPLICATIONS}

It is well known that different processes have significantly different learning rates [22]. Some researchers have associated this difference in learning rate with the different scientific principles that process technologies are associated with [7]. Others claim that combinations of learning curves pertaining to different machineries and introduced with different timing may explain the wide variability observed among organizational learning curves [23]. Learning rates may also differ across plants of the same firm that produce the same good with similar equipment in the same country $[24,25]$. Although many researchers have observed this variation in learning rates, this phenomenon has not been the subject of much systematic analysis [15].

In the empirical learning-curve research presented in the previous section, we observed different learning rates, in the same manufacturing environment even for the same products. The simple learning curve applied to batch production, provides indication that a multi-dimensional phenomenon is present.

An especially exciting challenge is how to model and assess learning in the context of tile manufacturing where product batches may be short, quality issues complex and where many different learning-rates are present for the same product. Figure 2 shows a potential production pattern that incorporates the phenomenon of learning within and learning between batches. The learning rate is accelerated within and between batches

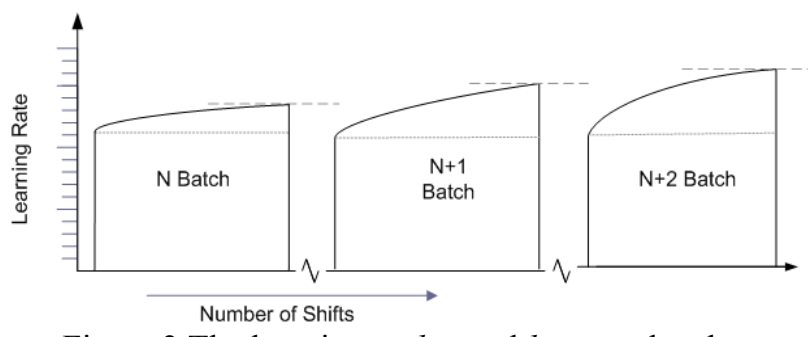

Figure 2 The learning within and between batches

Towill in [10] presented a similar model for batch production, introducing the "forgetting factor". In this theoretical model the increase in manufacturing time and labor cost is caused by the slippage in performance between batches. This method is able to predict batch production time based on the time-constant learning curve model and the "forgetting factor". This factor is the measure of the different performances (or slippage) between batches and depends on the elapsed time between the end of producing one batch and the start of the next.

Indeed the forgetting factor is a good theoretical approach to explain slippage between batches. But is "forgetting" suitable for our case study? In tile manufacturing there is no real production break; batches of different products are continuously, one after the other, produced in the line. There is no factor of forgetting in the production as all the techniques used between tile designs are very similar. The line set-up is responsible for the elapsed time between batches and is the cause for the initial slippage in the performance between batches.

A useful framework for conceptualizing learning is the autonomous/induced learning introduced by [26] and adopted by many other authors [27], [15], [4], [14]. The concept of learning within/between batches seems likely to be relevant with the autonomous/induced learning framework. Autonomous learning is the 'learning by doing' while induced learning is generated by deliberately undertaken engineering or managerial efforts. Research in induced learning seems able to pattern more complex behavior in products. In [15] induced learning is presented as a second order learning, incorporating the higher dynamics of a production system. To develop a collaborating approach, further research is needed in order to clarify the discrete characteristics of each framework, as well as their potential similarities or differences. 
Reliable conclusions are hard to come by. Further work needs to be done in order to determine the engineering factors and the parameters affecting the learning curves. A good practice would be engineering controlled experiments, using the production process as a laboratory, supported by statistical techniques for the analysis of more historical data. It is also essential to monitor as many operational variables as possible and correlate them with quality performance, in order to identify better what learning between batches is.

\section{CONCLUSIONS}

This article demonstrates an approach that can potentially aid in forecasting the quality performance of products in batches [13]. The approach is based in traditional learning curve theory yet it captures the dynamic nature of learning rates that grow faster from batch-to-batch in mature products. Our industrial data indicate that the learning curve in batch production is much more complex than previously thought with a mixture of learning occurring within and between batches.

Our approach provides strong indication that a phenomenon underlies the quality performance of tiles and emphasizes the further need to clarify the internal complex production process, combining a good estimation model that will be able to capture all the important factors, with actual production data from the shop floor.

Embracing Towill's [9] quote that "numbers are not substitute to understanding", our future work should focus beyond the conventional learning curve theory and concentrate on the rich dynamics that characterize learning in batch production.

\section{ACKNOWLEDGEMENTS}

This work is supported in part by a grant from Filkeram Johnson S.A., the leading ceramic tile manufacturer in Greece.

\section{REFERENCES}

[1] P. B. Kantor and W. I. Zangwill, "Theoretical foundation for a learning rate budget," Management Science, vol. 37, no. 3, pp. 315-330, 1991.

[2] C. Terwiesch and R. E. Bohn, "Learning and process improvement during production ramp-up," International Journal of Production Economics, vol. 70, no. 1, pp. 1-19, 2001.

[3] J. Vits and L. Gelders, "Performance improvement theory," International Journal of Production Economics, vol. 77, no. 3, pp. 285-298, 2002.

[4] C. H. Fine, "Quality improvement and learning in productive systems," Management Science, vol. 31, no. 10, pp. 1301-1315, 1989.

[5] J. Freiesleben and G. Schwarz, "Quality-triggered learning effects," Total Quality Management and Business Excellence, vol. 17, no. 7, pp. 825-834, 2006.
[6] M. Pruett and T. Howard, "Experience-based learning in innovation and production," $R \& D$ Management, vol. 32 , no. 2 , pp. 141-153, 2008

[7] J. D. Linton and S. T. Walsh, "Integrating innovation and learning curve theory: An enabler for moving nanotechnologies and other emerging process technologies into production," $R$ and D Management, vol. 34, no. 5, pp. 517-526, 2004.

[8] D. Biskup, "A state-of-the-art review on scheduling with learning effects," European Journal of Operational Research, vol. 188, no. 2, pp. 315-329, 2008.

[9] D. R. Towill, "Forecasting learning curves," International Journal of Forecasting, vol. 6, pp. 25-38, 1990.

[10] D. R. Towill, "Use of learning curve models for prediction of batch production performance." International Journal of Operations \& Production Management, vol. 5, no. 2, pp. 13-24, 1985.

[11] S. Globerson and D. Gold, "Statistical attributes of the power learning curve model," International Journal of Production Research, vol. 35, no. 3, pp. 699-711, 1997.

[12] M. Y. Jaber and M. Bonney, "Lot sizing with learning and forgetting in set-ups and in product quality," International Journal of Production Economics, vol. 83, no. 1, pp. 95-111, 2003.

[13] A. P. Chatzimichali and V. D. Tourassis, , "An Empirical Investigation of Learning Curve Laws in the Tile Manufacturing Industry," in Proc. IEEM 2007: 2007 IEEE International Conference on Industrial Engineering and Engineering Management, pp. 1110-1114.

[14] M. A. Lapré, A. S. Mukherjee and L. N. Van Wassenhove, "Behind the learning curve: Linking learning activities to waste reduction," Management Science., vol. 46, no. 5, pp. 597-611, 2000.

[15] P. S. Adler and K. B. Clark, "Behind the learning curve: A sketch of the learning process," Management Science, vol. 37, no. 3, pp. 267-281, 1991.

[16] D. Z. Levin, "Organizational learning and the transfer of knowledge: An investigation of quality improvement," Organization Science, vol. 11, no. 6, pp. 630-647, 2000.

[17] W. I. Zangwill and P. B. Kantor, "Toward a theory of continuous improvement and the learning curve," Management Science, vol. 44, no. 7, pp. 910-920, 1998.

[18] G. Li and S. Rajagopalan, "The impact of quality on learning," Journal of Operations Management, vol. 15, no. 3, pp. 181191, 1997.

[19] M. M. Naim and D. R. Towill, "An engineering approach to LSE modelling of experience curves in the electricity supply industry," Journal of Forecasting, Netherlands, vol. 6, no. 4, pp. 549-556, 1990.

[20] A. Newell and P. S. Rosenbloom, "Mechanisms of skill acquisition and the law of practice," Mechanisms of Skill Acquisition and the Law of Practice, 1981.

[21] T. Wright, "Factors affecting the cost in airplanes," Journal of Aeronautical Science, vol. 3, no. 2, pp. 122-128, 1936.

[22] L. E. Yelle, "The learning curve: Historical review and comprehensive survey," Decision Sciences, vol. 10, no. 2, pp. 302-328, 1979.

[23] G. Fioretti, "A connectionist model of the organizational learning curve," Computational and Mathematical Organization Theory, vol. 13, no. 1, pp. 1-16, 2007.

[24] L. Argote, "Organizational Learning: Creating, Retaining and Transferring Knowledge", Kluwer, Boston, 1999.

[25] L. Argote and D. Epple, "Learning curves in manufacturing," Science, vol. 247, no. 4945, pp. 920-924, 1990.

[26] F. K. Levy, "Adaptation in the production process," Management Science, vol. 11, no. 6, 1965.

[27] D. A. Serel, M. Dada, H. Moskowitz and R. D. Plante, "Investing in quality under autonomous and induced learning," IIE Transactions (Institute of Industrial Engineers), vol. 35, no. 6, pp. 545-555, 2003. 